\title{
The Influence of Alliance Innovation Network Structure upon Enterprise Innovation: A Case Study of China's Energy-Saving and Environment-protection Industry
}

\author{
Meng $X u^{1}$ \\ ${ }^{1}$ Shangqiu Normal University, China \\ Correspondence: Meng Xu, Shangqiu Normal University, China. E-mail: xumeng-sq@126.com
}

Received: November 24, 2017

Accepted: December 25, 2017 Online Published: January 15, 2018

doi:10.5539/ijbm.v13n2p208

URL: https://doi.org/10.5539/ijbm.v13n2p208

\begin{abstract}
The Energy-saving and environment-protection industry, an important strategic and emerging industry in China, will develop into a pillar industry. In view of global climate change, environmental pollution, resource depletion and the defects and deficiencies in traditional technology, technology and product innovation constitute the lifeline of energy-saving and environment-protection industry. The alliance network of enterprises will influence, stimulate, and regulate enterprise innovation greatly. A comprehensive analysis of alliance data of China's energy-saving and environment-protection industry from 2000 to 2013 by using Ucinet software can reveal the network structure parameters such as degree, clique number, average path length, clustering coefficient, and betweenness centrality, which reflects different types of enterprise networks and different positions of enterprises in different types of networks. A negative regression analysis of enterprise patent data and network structure parameters by using Stata software can make some conclusions that the influences of network characteristics on enterprise innovation reach the maximum in the second year of the window period end, that innovation accumulation, clustering coefficient, betweenness centrality are related to the enterprise innovation, that clique number, network density are negatively related to the enterprise innovation, and that there is an inverted $U$ relationship between average path length and enterprise innovation. It is suggested to increase the accumulation level of innovation, appropriately control the network density, reduce the average path length, improve the betweenness centrality and clustering coefficient of enterprises, so as to improve the overall innovation level.
\end{abstract}

Keywords: Energy-saving and environment-protection industry, alliance innovation network, enterprise innovation, social network analysis, negative regression

\section{Introduction}

\subsection{Research Background}

Innovation is the main way for enterprises and countries to gain competitiveness, and the main means for enterprises to obtain excess profits. Many enterprises lack innovation and core technology, and are under the control of other countries in these respects. Many Chinese enterprises with foreign businesses are not in the key link of the global industry chain, and their product pricing ability is weak and the added value of production is low. As a result, they are subject to other enterprises. In recent years, scholars have begun to explore the influencing factors of innovation in various aspects, among which the enterprise alliance cooperation mechanism has also attracted attention.

\subsubsection{Innovation Costs and Risks Require Enterprise Alliance Cooperation}

With the continuous progress of technology, the difficulty and risk of innovation further increase. For enterprises, innovation based on their internal resources has been unable to meet the needs of market competition. Enterprises gain competitive advantage by their technology and innovation. It requires a lot of money, manpower and time. At the same time, enterprises bear huge market risks. Innovation costs and risks cause enterprises to cooperate in alliances. With the deepening of postwar economic globalization, more and more enterprises begin to form strategic alliances to share resources and increase mutual innovation advantages. Enterprise strategic alliances help to enhance the core competitiveness of enterprises, economies of scale and scope, reduce operational risks and prevent excessive competition (Zhang, 2001). Strategic alliances can improve the competitiveness of enterprises in the areas of institutional and organizational (Zhou, 2000). The knowledge 
alliance helps enterprises not only acquire explicit knowledge, but also learn tacit knowledge and create new capabilities(Shen Zuzhi, 2003). It can update or create its core competence through strategic management .

1.1.2 The Innovation Behavior of Enterprises Is Stimulated, Influenced and Restricted by the Alliance Innovation Network

In the process of innovation, various kinds of alliances and cooperation, formed by enterprises, is called alliance innovation network. From a global perspective, a certain amount of enterprise innovation alliance forms a sparse alliance innovation network, which stimulates, influences and restricts the innovative behavior of enterprises. More and more scholars have proved that network organization is beneficial to enterprise technological innovation. Network practice, management orientation, external knowledge and network embeddedness have influence on innovation performance (Chen, 2016, 2017). There is a main effect between the local and super local double embeddedness of cluster enterprises and the promotion of innovation capability, network strength, persistence and network diversity have a significant impact on the innovation capability of cluster enterprises(Wei, 2014, 2016). The strength of alliance relations has an inverted $U$ effect on corporate innovation performance, and the quality of alliance relationship has a positive impact on enterprise innovation performance (Xie, 2016, 2017). In the process of technological innovation in the industry alliance, relational embeddedness brings benefits, in which weak relationship has a positive impact on technological innovation, while strong ties have a U effect on technological innovation (Wang, 2017). The alliance network characteristics of small and micro technology enterprises play a significant role in promoting innovation performance (Zhang, 2016). Researching and developing cooperation can significantly promote the enterprise innovation, and the close relationship of alliance network is an important means to promote radical innovation (Gao, 2016).

\subsection{Research Methods: Social Network Analysis}

From the earliest interpersonal network to the later social network research, multidisciplinary integration formed a complete social network theory, methods and techniques. Granovetter (1984) points out that the theoretical hypothesis of traditional economics, pure economic relations, does not exist in real life, and that economic activities can not bypass social relations. He opened up a new field of economic sociology and established network analysis methods. In recent years, with the development of computer technology and of network analysis software, the analysis of the social network with highly complex structure has gradually become an important research object and methods. At the same time, social network and whole network analysis are gradually permeating into the field of economic management. This trend has been around the world for more than 10 years. In recent years, scholars have begun to try to build an alliance network, and they extends the interrelated analysis layers from isolated individual to an interrelated network. Zhao Yan et al. think that the network centrality of enterprises has an lagged positive effect on enterprise innovation(Zhao, 2017); the small world of strategic alliance network positively influences innovation performance (Zhao, 2013); the non redundant links and aggregation of enterprise alliance network nodes have a potential impact on enterprise innovation (Zhao, 2013); the structure holes of the alliance network can significantly promote the innovation performance of enterprises(Zhao, 2012); faction and knowledge flow have positive influence on alliance network innovation performance (Zhao, 2016).

\subsection{Research Purpose and Significance}

Energy-saving and environment-protection industry has become one of the strategic emerging industries to accelerate the cultivation and development of China. A Development Plan of the National Strategic Emerging Industry From 2016 to 2020 proposed that we should focus on the construction of ecological civilization and climate change, comprehensively promote energy-efficient and advanced environment-protection and resource-recycling industry system construction, and promote energy-saving environmental protection industry to become a pillar industry. Energy-saving and environment-protection enterprise's research and developing high-tech equipment should be in accordance with the specific conditions of environmental pollution and our national requirements for environmental protection, energy consumption, and resource consumption (Note 1), which requires a large number of innovative behavior. At the same time, there are many strategic alliances between enterprises in order to promote technological cooperation and accelerate innovation. At present, there is no literature published about the relationship between alliance structure and enterprise innovation behavior of China's energy-saving and environment-protection industry. It is necessary for us to do pioneering research on it. Through this study, we should determine whether there is a connection between these two and their specific forms (mathematical expressions). On this basis, we can draw some useful inferences and suggestions for the government, industry and enterprises. 


\section{Theoretical Analysis}

\subsection{Enterprise Innovation Function}

Enterprise's innovation ability can be restricted by many factors. We simply divide these factors into two aspects: network factors (Song, 2014) and other factors. Enterprise innovation function can be put forward as follows:

$$
\mathrm{Y}(\mathrm{i})=\mathrm{f}\left(\text { Network_factor }_{\mathrm{i}}, \text { Other_factor }_{\mathrm{i}}\right)
$$

"Y" represents the total amount of innovation, and " $\mathrm{i}$ " represents the ith company. The network factors include the following indexes: degree, betweenness centrality, local efficiency, network density, clustering coefficient, average path length, cliques numbers, core values, etc. Other factors include individual factors such as enterprise scale, enterprise nature, industry characteristics, enterprise culture, enterprise history, Researching and developing investment intensity, management characteristics, enterprise strategy choice and macro factors, such as international politics, economy, national law, social development, government policy and so on.

This paper focuses on the influence of alliance network on enterprise innovation, and we use the "accumulation of innovation" variables to measure all other factors as a whole. In later calculation, we can find that "accumulation of innovation" is an important explanation for enterprise innovation. At the same time, a number of network factors also make partial explanations for enterprise innovation.

If $\mathrm{Xj}, \mathrm{Xk}(\mathrm{j}, \mathrm{k}=0,1,2,3, \ldots)$ represents the $\mathrm{jth}$ (or $\mathrm{kth}$ ) factor, the innovation function (1) can be written as:

$$
\mathrm{Y}(\mathrm{i})=\mathrm{f}\left(\mathrm{X}_{0}, \mathrm{X}_{1}, \mathrm{X}_{2} \ldots \ldots\right)
$$

$X_{0}$ represents accumulation of innovation. When $\mathrm{j}, \mathrm{k} \neq 0, \mathrm{X}_{\mathrm{j}}$ and $\mathrm{X}_{\mathrm{k}}$ represent the network structure parameters.

When individual factors of enterprise and network factors affect the innovation linearly, the function can be written in the following form:

$$
\mathrm{Y}(\mathrm{i})=\sum \mathrm{f}_{\mathrm{j}}\left(\mathrm{X}_{\mathrm{ji}}\right)
$$

Considering the possible cross effects between factors:

$$
Y(i)=\sum_{i, j} f_{j}\left(X_{j i}\right)+\sum_{i, j, k} f_{j k}\left(X_{j i} X_{k i}\right)
$$

\subsection{The Nature of the Single Factor Innovation Function}

This paper next analyzes the nature of $\mathrm{f}_{\mathrm{j}}\left(\mathrm{X}_{\mathrm{ji}}\right)$ (the influence function of network factors on enterprise innovation) when $\mathrm{j} \neq 0$.

Network factors affect enterprise innovation mainly through two aspects which are the availability and convenience of innovation resource acquisition (AC), and the management cost of alliance relationship (Cost)(Zhong Shuhua, 1998).

$$
\mathrm{f}\left(\mathrm{X}_{\mathrm{i}}\right)=\mathrm{AC}\left(\mathrm{X}_{\mathrm{i}}\right)-\operatorname{Cost}\left(\mathrm{X}_{\mathrm{i}}\right)
$$

Next, we analyze the property of this function by using the simplest network structure parameter (degree).

The first part of Equation (4) plays a positive role in promoting enterprise innovation. With the increase of alliance relationship, the status, importance and centrality of enterprises in the network are increasing, and the availability and convenience of innovation resources are also increasing. It is obvious that the AC function goes through the origin and rises monotonically. When the enterprise has only a few alliances, the enterprise is on the edge of the alliance network, and the information is limited by the core enterprises, and lacks the right to speak. The benefits of the alliance relationship are not easy to show. With the increase of alliances, enterprises are gradually approaching the central position of the network, and they can get more information and speak more right. According to economics theory, when the resource inputs began to gradually increase from zero, it initially manifests as economies of scale (increasing marginal revenue). After reaching a certain critical value, it manifests as economies of scale (decreasing marginal revenue). It is assumed that the slope of the AC function increases first and then decreases, and eventually approaches zero. That is to say, with the increase of the number of alliances, the unit income first rises gradually, then decreases gradually until it disappears. The second part of equation (4) has negative influence on enterprise innovation, and its absolute value increases with the increase of alliance relationship. It is obvious that the Cost function is also monotonically increasing through the origin, and its slope has no obvious tendency to change. We assume that the slope is fixed (Jin, 2005; Fan, 2003; Gu, 2001).

Obviously, when degree reaches the maximum theoretical value of Dmax (enterprise sets up alliances with all other enterprises), the Cost function value should be greater than that of AC function, and obviously no 
enterprise does so (see Figure 1, the upper half). From the second half of Figure 1, we can see that $\mathrm{f}($ degree) gets the maximum Fmax on a suitable degree $(\mathrm{d} 0)$. It should be close to the mean or median of the number of alliances selected by companies in real life.

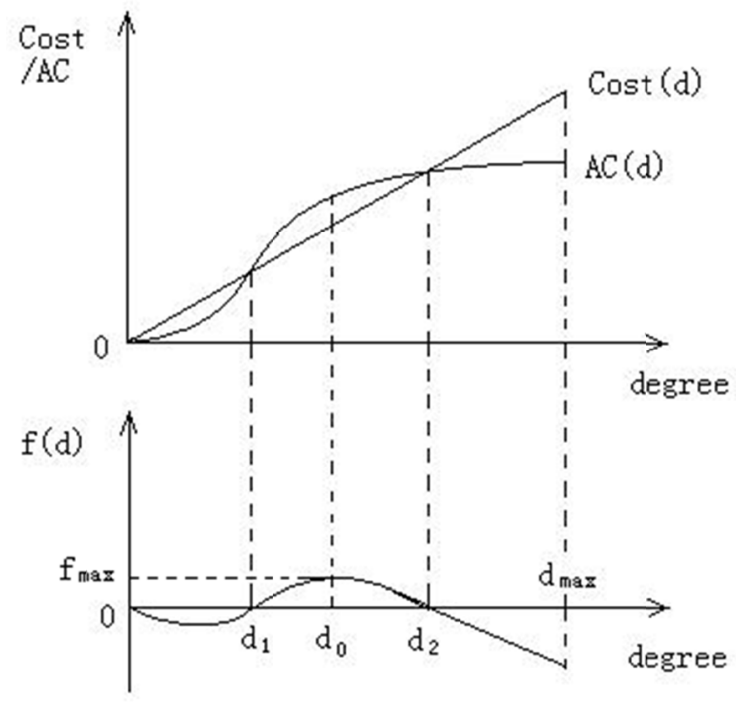

Figure 1. Schematic diagram of innovation function $\mathrm{F}$ and its component functions $\mathrm{AC}$ and Cost

Note. The independent variable is network structure parameter: degree

The above is only a rough theoretical analysis, and the properties of functions AC and Cost do not necessarily agree with our analysis. The influence of various factors on innovation may be nonlinear or linear, and there may be cross effects between them. All of these need to be verified by analysis of concrete evidence.

\section{The Process of Model Estimation}

We choose (3) and (4) as the estimation models. On the basis of (3), we introduce the cross terms and the square terms.

\subsection{Data Sources}

The data used in this study are alliance data and enterprise application patent data. The alliance relation data is used to draw the alliance network graph and calculate the network structure parameter values. The alliance relationship data is from the SDC Platinum database in the United states. By collecting, collating and proofreading the relevant data, we got the enterprise alliance database of China's energy-saving and environment-protection industry in 2000 -2013. We assume that all enterprise alliances are Innovation Alliances, and alliances last for 4 years, that is to say, the alliance network is built on 4-year windows (2000-2003, 2001-2004...2010-2013 ). The social network analysis software Ucinet was used to calculate the various network structure indicators needed. Enterprise patent data can be used to measure the enterprise's innovation ability. In this study, the patent information service platform of China Intellectual Property Network (www.cnipr.com) was used to inquire about the patent data of the relevant enterprises from 2000 to 2013 . We assume that the impact of coalition formation on firm innovation occurs in the same year or 1, 2, 3 years later. In the estimation process, we make the dependent variable lag $0,1,2,3$ years.

$$
Y_{i t+0(1,2,3)}(i)=\sum_{i, j} f_{j}\left(X_{j i t}\right)+\sum_{i, j, k} f_{j k}\left(X_{j i t} \times X_{k i t}\right),(m=n, n+1, n+2, n+3)
$$

In the upper form, $\mathrm{i}, \mathrm{j}, \mathrm{k}$ are enterprise marks, and $\mathbf{t}$ is the year mark. 


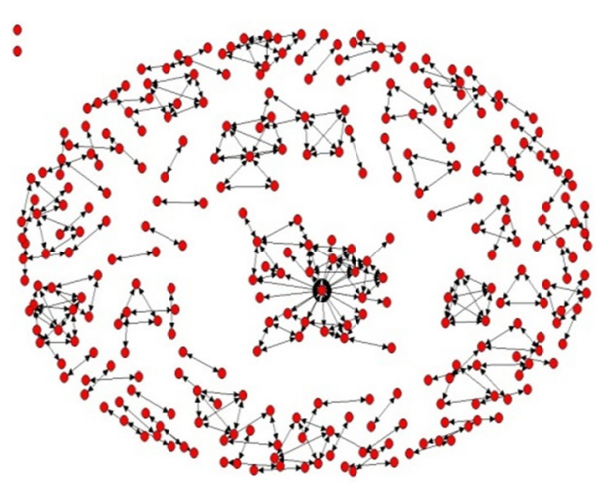

Figure 2. Inter-firm alliance network of China's energy-saving and environment-protection industry (2000-2013)

Note. The dots represent different enterprises, and the segments with arrowheads represent alliance relationships. The diagram is generated using the Netdraw module in Ucinet6.0. we can see that only 2 enterprises have established alliances with more than 5 enterprises, and most enterprises have established alliances with 1-2 enterprises.

\subsection{Parameters}

\subsubsection{Dependent Variables: Number of Patents (Patentsit)}

Most of the companies in energy-saving and environment-protection industries are high-tech enterprises, which mainly protect their innovation achievements through patent applications. Therefore, the number of patents is an important indicator of innovation capability of enterprises. $\mathrm{P}_{0}, \mathrm{P}_{1}, \mathrm{P}_{2}, \mathrm{P}_{3}$ represent the patents of $0,1,2,3$ years lag respectively.

\subsubsection{Independent variable}

1) Accumulation of innovation (PRE)

Pre5=Patents-5+Patents-4+Patents-3+Patents-2+Patents-1

2) Degree (D)

The number of enterprises which have direct alliances with an enterprisein, or the number of alliances (edges) of an enterprise, is called degree.

3) Network density (ND);

The average degree of cohesion between firms in an alliance network.

$$
\text { Density }=2 \sum T_{\mathrm{ij}} /[\mathrm{n}(\mathrm{n}-1)] \text { (undirected network) }
$$

In the upper model, $\mathrm{n}$ is the number of enterprises in an alliance network; i and $\mathrm{j}$ represent enterprises; $\sum \mathrm{T}_{\mathrm{ij}}$ represents the total number of all enterprise I and $\mathrm{J}$ alliances.

4) Average network distance (Average path length, APL);

Usually it is expressed by the average distance between enterprises in a network (step size or edge number).

$$
\overline{\mathrm{d}}=\frac{1}{n(\mathrm{n}-1)} \sum_{i \neq j} d_{i j}
$$

Dij is the minimum number of edge of paths between two enterprises (I, J) in a network diagram, and $n$ is the number of enterprises in an alliance network.

5) Clustering coefficient(CC);

$$
\begin{gathered}
C C_{i}=\frac{3 N_{\Delta}(i)}{N_{3}(i)} \\
\left.N_{\Delta}(i)=\sum_{k>j} a_{i j} a_{j k} a_{i k}, \quad N_{3}(i)=\sum_{k>j} a_{i j} a_{i k}\right)
\end{gathered}
$$

$\mathrm{N} \Delta(\mathrm{i})$ is the total number of closed three tuples containing the enterprise $\mathrm{I}$ in the network. $\mathrm{N}_{3}(\mathrm{i})$ is the total 
number of open three tuples containing the enterprise I in the network, and aij is the matrix element of the adjacency matrix of the network. The clustering coefficient of the whole network can be recorded as:

$$
C C=\frac{1}{n} \sum_{i=1}^{n} C C_{i}=\frac{1}{n} \sum_{i=1}^{n} \frac{3 N_{\Delta}(i)}{N_{3}(i)}
$$

6) Betweenness centrality(BC);

$$
B C_{i}=\sum_{j<k} \frac{g_{j k}(i)}{g_{j k}}
$$

Here is the absolute centrality. Gjk represents the number of the shortest paths between the node $\mathrm{j}$ and $\mathrm{K}$. Gjk(i) represents the number of the shortest paths between node $\mathrm{j}$ and $\mathrm{K}$ through the node I. The greater the $\mathrm{BC}$ value, the greater the enterprise I is at the center of the network.

7) Efficiency(E);

$$
\text { Efficiency }=\mathbf{1}-\frac{2 \mathrm{t}}{\mathrm{n}^{2}}
$$

Here $t$ is the number of connections in the individual network of the node $i$ (excluding the number of connections to the central point), and $\mathrm{N}$ is the individual network size of the node $\mathrm{i}$ (excluding self point).

8) Cliques number $(\mathrm{CN})$;

Cliques refer to the largest complete subgraph that includes at least 3 enterprises, where any of the two firms has an alliance. $\mathrm{CN}$ is the number of cliques that exist in a network.

9) Core degree (coreness, values, CV)

$$
\text { Coreness values }=\operatorname{MAX}(\mathrm{Ki})
$$

$\mathrm{Ki}$ is the $\mathrm{K}$ value of a point in the I $\mathrm{K}$ - kernel (from $\mathrm{K} 1$ to $\mathrm{Ki}$ ).

\subsection{STATA Estimation Process}

3.3.1 Input the required variable data into the STATA database. First, descriptive and correlation analysis is used.

Table 1. Descriptive and correlation table of variables (obs=706)

\begin{tabular}{lllllllllllll}
\hline Var & Mean & S.D & Min & Max & PRE & D & E & CC & APL & ND & BC & CN \\
\hline PRE & 222.54 & 1452.98 & 0.00 & 17513.00 & 1 & & & & & & & \\
D & 1.68 & 1.22 & 0.00 & 17.00 & 0.09 & 1 & & & & & & \\
E & 0.79 & 0.29 & 0.25 & 1.00 & -0.10 & -0.91 & 1 & & & & & \\
CC & 0.93 & 0.03 & 0.88 & 0.97 & -0.01 & 0.09 & -0.11 & 1 & & & & \\
APL & 1.25 & 0.35 & 1.02 & 2.08 & -0.06 & 0.30 & -0.30 & -0.02 & 1 & & & \\
ND & 0.04 & 0.00 & 0.01 & 0.07 & 0.01 & -0.06 & 0.07 & -0.02 & -0.07 & 1 & & \\
BC & 0.82 & 9.15 & 0.00 & 189.50 & -0.01 & 0.32 & -0.05 & -0.02 & 0.18 & -0.01 & 1 & \\
CN & 9.21 & 1.16 & 5.00 & 16.00 & -0.02 & -0.07 & 0.08 & -0.05 & -0.06 & 0.94 & -0.01 & 1 \\
CV & 1.59 & 0.89 & 0.00 & 4.00 & 0.10 & 0.98 & -0.95 & 0.11 & 0.27 & -0.06 & 0.16 & -0.07 \\
$\mathrm{P}_{0}$ & 51.56 & 259.60 & 0.00 & 3248.00 & & & & & & & & 1 \\
$\mathrm{P}_{1}$ & 50.68 & 238.55 & 0.00 & 2739.00 & & & & & & & & \\
$\mathrm{P}_{2}$ & 49.37 & 232.59 & 0.00 & 2439.00 & & & & & & & & \\
$\mathrm{P}_{3}$ & 47.95 & 230.59 & 0.00 & 2439.00 & & & & & & & & \\
\hline
\end{tabular}

The number of patents, as a counting variable, is a highly discrete. Its variance is significantly greater than the mean. Therefore, this paper chooses the generalized Poisson regression model, that is to say, the negative binomial regression model for empirical analysis, which allows excessive dispersion. 
ND was highly correlated with CN. CV, D, and E were highly correlated with each other. In the latter model estimation process, variables $\mathrm{E}, \mathrm{ND}$, and $\mathrm{CV}$ are excluded.

\subsubsection{Build Models and Estimate}

After the establishment of enterprise alliance, it takes a certain period of time to produce obvious effect on innovation. In order to investigate the length of the lag period, we establish the negative binomial models with different lag stages, and use Stata to estimate them. The results are shown in table 2.

$$
\mathrm{LN}\left(\mathrm{P}_{\mathrm{it}+0}(1,2,3)\right)=\mathrm{a}_{0}+\mathrm{a}_{1} \mathrm{PRE}_{\mathrm{it}}+\mathrm{a}_{2} \mathrm{D}_{\mathrm{it}}+\mathrm{a}_{3} \mathrm{CC}_{\mathrm{it}}+\mathrm{a}_{4} \mathrm{APL}_{\mathrm{it}}+\mathrm{a}_{5} \mathrm{BC}_{\mathrm{it}}+\mathrm{a}_{6} \mathrm{CN}_{\mathrm{it}}+\mu
$$

I refers to the firm, $\mathrm{i}=1,2, \ldots . .282$. T refers to the year, and $0(1,2,3)$ is the number of lag periods.

Table 2. STATA negative binomial regression models $(\mathrm{Obs}=706)$

\begin{tabular}{lllllllll}
\hline & $(1)$ & $(2)$ & $(3)$ & $(4)$ & $(5)$ & $(6)$ & $(7)$ & $(8)$ \\
& $\mathrm{P}_{0}$ & $\mathrm{P}_{0}$ & $\mathrm{P}_{1}$ & $\mathrm{P}_{1}$ & $\mathrm{P}_{2}$ & $\mathrm{P}_{2}$ & $\mathrm{P}_{3}$ & $\mathrm{P}_{3}$ \\
\hline PRE & $0.00331^{* * *}$ & $0.00818^{* * *}$ & $0.00327^{* * *}$ & $0.00322^{* * *}$ & $0.00308^{* * *}$ & $0.00314^{* * *}$ & $0.00312^{* * *}$ & $0.00308^{* * *}$ \\
$\mathrm{D}$ & 0.180 & & 0.104 & & 0.0921 & & 0.0568 & \\
$\mathrm{CC}$ & 6.414 & & $8.820^{*}$ & $2.002^{* * *}$ & $11.11^{* * *}$ & $11.49^{* * *}$ & $13.50^{* * *}$ & $12.37^{* * *}$ \\
$\mathrm{APL}$ & $-1.589^{* * *}$ & & $-1.395^{* *}$ & & $-1.328^{* *}$ & $-1.272^{* *}$ & -0.821 & \\
$\mathrm{BC}$ & 0.110 & & 0.116 & & 0.138 & $0.150^{*}$ & 0.127 & \\
$\mathrm{CN}$ & -0.313 & & -0.544 & & $-0.772^{*}$ & $-0.803^{*}$ & $-1.063^{* *}$ & $-1.031^{* *}$ \\
chi2 & 225.0 & 89.68 & 258.8 & 263.9 & 276.2 & 275.7 & 285.2 & 291.7 \\
prob & 0.0000 & 0.0000 & 0.0000 & 0.0000 & 0.0000 & 0.0000 & 0.0000 & 0.0000 \\
loglikelihood & -1227.0 & -1264.7 & -1267.6 & -1272.9 & -1274.6 & -1274.8 & -1213.0 & -1217.9 \\
\hline
\end{tabular}

Note. Significant at $* p<0.1, * * \boldsymbol{p}<0.05, * * * p<0.01$.

All models have high credibility. The lag periods of patent 0 , patent1, patent 2 , and patent 3 were $0,1,2,3$, respectively. Model 1, 3, 5, and 7 are full-variable models, and do not exclude variables that are not significant. Models 2, 4, 6, 8 pick out all the less significant independent variables.

3.3.3 Model 6 Is Relatively Optimal

On the basis of model 6, this paper tries to introduce cross terms, but no significant items appear.

Table 3. Stata negative binomial regression models with cross item (obs=706)

\begin{tabular}{|c|c|c|c|c|c|c|c|c|c|}
\hline & (9) & (10) & (11) & (12) & (13) & (14) & (15) & (16) & (17) \\
\hline & $\mathrm{P}_{2}$ & $\mathrm{P}_{2}$ & $\mathrm{P}_{2}$ & $\mathrm{P}_{2}$ & $\mathrm{P}_{2}$ & $\mathrm{P}_{2}$ & $\mathrm{P}_{2}$ & $\mathrm{P}_{2}$ & $\mathrm{P}_{2}$ \\
\hline pre & $0.00308 * * *$ & $0.00310 * * *$ & $0.00312 * * *$ & $0.00308^{* * *}$ & $0.00309 * * *$ & $0.00314 * * *$ & $0.00313^{* * *}$ & $0.00314 * * *$ & $0.00296^{* * *}$ \\
\hline $\mathrm{cc}$ & $11.04 * *$ & $11.22 * * *$ & $11.66^{* * *}$ & $11.17 * * *$ & $16.29 * *$ & $11.61 * * *$ & $11.41 * * *$ & $11.49 * * *$ & 10.96 \\
\hline apl & $-1.326 * *$ & $-1.390 * *$ & $-1.335^{* *}$ & $-1.325 * *$ & 5.307 & $-1.266 * *$ & $-1.279 * *$ & $-1.272 * *$ & 8.539 \\
\hline $\mathrm{bc}$ & $0.139 *$ & 0.136 & 0.544 & $0.139 *$ & $0.146^{*}$ & 6.252 & -0.420 & $0.150 *$ & 3.456 \\
\hline $\mathrm{cn}$ & $-0.764 *$ & $-0.770 *$ & $-0.813^{*}$ & $-0.777^{*}$ & -1.292 & $-0.817^{*}$ & $-0.793 *$ & $-0.803^{*}$ & -0.808 \\
\hline $\mathrm{D} * \mathrm{cc}$ & 0.0930 & & & & & & & & 5.643 \\
\hline D*apl & & 0.0509 & & & & & & & -0.373 \\
\hline $\mathrm{D} * \mathrm{bc}$ & & & -0.0767 & & & & & & -0.116 \\
\hline $\mathrm{D}^{*} \mathrm{cn}$ & & & & 0.00953 & & & & & -0.513 \\
\hline Cc*apl & & & & & -7.125 & & & & -10.29 \\
\hline $\mathrm{Cc}^{*} \mathrm{bc}$ & & & & & & -6.641 & & & -4.647 \\
\hline $\mathrm{Apl}^{*} \mathrm{bc}$ & & & & & & & 0.276 & & 0.773 \\
\hline $\mathrm{Bc} * \mathrm{cn}$ & & & & & & & & 0 & 0 \\
\hline$N$ & 706 & 706 & 706 & 706 & 706 & 706 & 706 & 706 & 706 \\
\hline chi2 & 276.2 & 276.3 & 276.7 & 276.2 & 279.2 & 275.8 & 275.6 & 275.7 & 279.0 \\
\hline aic & 2563.3 & 2563.4 & 2562.8 & 2563.3 & 2562.6 & 2563.4 & 2563.5 & 2561.5 & 2572.1 \\
\hline loglikelihood & -1274.7 & -1274.7 & -1274.4 & -1274.7 & -1274.3 & -1274.7 & -1274.7 & -1274.8 & -1273.1 \\
\hline
\end{tabular}

Note. Significant at ${ }^{*} p<0.1,{ }^{* *} p<0.05,{ }^{* * *} p<0.01$. If the cross terms $\mathrm{Cc}^{*} \mathrm{cn}$ and a*cn are added to the model, the result cannot be calculated. 
3.3.4 We Introduce Square Terms One by One to Model 6, and Find That Only the Square Term Of APL Is Significant

Table 4. STATA negative binomial regression models with two items (Obs=706)

\begin{tabular}{|c|c|c|c|c|c|c|c|c|}
\hline & (18) & (19) & (20) & (21) & (22) & (23) & (24) & (25) \\
\hline & $\mathrm{p} 2$ & $\mathrm{p} 2$ & $\mathrm{p} 2$ & $\mathrm{p} 2$ & $\mathrm{p} 2$ & $\mathrm{p} 2$ & $\mathrm{p} 2$ & $\mathrm{P} 2$ \\
\hline pre & $0.00308^{* * *}$ & $0.00315^{* * *}$ & $0.00306^{* * *}$ & $0.00299^{* * *}$ & $0.00313^{* * *}$ & $0.00308^{* * *}$ & $0.00302^{* * *}$ & $0.00305^{* * *}$ \\
\hline $\mathrm{cc}$ & $11.11^{* *}$ & $11.53^{* * *}$ & 4.634 & 5.495 & $11.63^{* * *}$ & $11.13^{* * *}$ & -9.046 & \\
\hline apl & $-1.328^{* *}$ & $-1.263^{* *}$ & $15.82^{* *}$ & $-1.221^{* *}$ & $-1.338^{* *}$ & $-1.326^{* *}$ & 13.92 & $18.81^{* * *}$ \\
\hline $\mathrm{bc}$ & 0.132 & $0.150^{*}$ & $0.175^{* *}$ & $0.153^{*}$ & 0.268 & $0.148^{*}$ & 0.692 & $0.175^{* *}$ \\
\hline $\mathrm{cn}$ & $-0.764^{*}$ & $-0.811^{*}$ & $-1.440^{* *}$ & $-2.709^{*}$ & $-0.809^{*}$ & $-0.766^{*}$ & -2.647 & $-1.197^{* *}$ \\
\hline $\mathrm{D}^{2}$ & 0.0227 & & & & & & -0.433 & \\
\hline$e^{2}$ & & 0.0298 & & & & & 1.158 & \\
\hline $\mathrm{apl}^{2}$ & & & $-5.545^{* *}$ & & & & -4.925 & $-6.513^{* * *}$ \\
\hline $\mathrm{nd}^{2}$ & & & & 14817.9 & & & 11913.0 & \\
\hline$b c^{2}$ & & & & & -0.00344 & & -0.00847 & \\
\hline $\mathrm{cv}^{2}$ & & & & & & 0.0207 & 0.537 & \\
\hline $\mathrm{cc}^{2}$ & & & & & & & 6.368 & \\
\hline$N$ & 706 & 706 & 706 & 706 & 706 & 706 & 706 & 706 \\
\hline chi2 & 276.1 & 275.7 & 283.7 & 279.9 & 276.6 & 276.1 & 282.6 & 282.4 \\
\hline aic & 2563.3 & 2563.5 & 2557.4 & 2560.7 & 2562.6 & 2563.3 & 2565.8 & 2556.3 \\
\hline loglikelihood & -1274.6 & -1274.8 & -1271.7 & -1273.4 & -1274.3 & -1274.7 & -1269.9 & -1272.2 \\
\hline
\end{tabular}

Note. Significant at ${ }^{*} p<0.1,{ }^{* *} p<0.05,{ }^{* * *} p<0.01$. We remove the CC variable from model 20 and recalculate to obtain model 25 .

3.3.5 We can get two ideal innovation functions from the 3.3.2 and 3.3.4:

$$
\begin{aligned}
& \text { model 6: } \mathrm{LN}(\mathrm{P} 2)=0.00314 \mathrm{PRE}+11.49 \mathrm{CC}-1.272 \mathrm{APL} \quad+0.15 \mathrm{BC}-0.803 \mathrm{CN}+\mu \\
& \text { model 25: } \mathrm{LN}(\mathrm{P} 2)=0.00305 \mathrm{PRE}+18.81 \mathrm{APL}+0.175 \mathrm{BC}-1.197 \mathrm{CN}-6.513(\mathrm{APL}) 2+\mu
\end{aligned}
$$

(17) can be transformed into:

$$
\mathrm{LN}(\mathrm{P} 2)=0.00305 \mathrm{PRE}-6.513(\mathrm{APL}-1.444) 2+0.175 \mathrm{BC}-1.197 \mathrm{CN}+13.58+\mu
$$

3.3.6 CC may be associated with $\mathrm{APL}^{2}$. We establish the linear model and use the Stata software to get the regression results:

Table 5. regression results of CC-APL ${ }^{2}$ model

\begin{tabular}{llll}
\hline $\mathrm{c}$ & Coef. & Std. Err. & $\mathrm{t}$ \\
\hline APL & $0.234^{* * *}$ & 0.0382 & 6.13 \\
$(\mathrm{APL})^{2}$ & $-0.0762^{* * *}$ & 0.0123 & -6.19 \\
$\mathrm{C}$ & $0.763^{* * *}$ & 0.0271 & 28.14 \\
Number of obs & 706 & R-squared & 0.0397 \\
F( 2, 943) & $19.5^{* * *}$ & Adj R-squared & 0.0377 \\
& & Root MSE & 0.02694 \\
\hline
\end{tabular}

Note. Significant at ${ }^{* * *} p<0.001$.

We can see that although the R-squared is small, the $\mathrm{F}$ statistic of the equation and the $\mathrm{T}$ statistic of each coefficient pass the significance test. We can think that the following relationship exists: 


$$
\mathrm{CC}=0.763+0.234 \mathrm{APL}-0.0762(\mathrm{APL})^{2}+\mu
$$

The upper forms can be deformed into:

$$
\mathrm{CC}=0.942-0.0762(\mathrm{APL}-1.535)^{2}+\mu
$$

\section{Analysis Results}

Observe the calculations above, we can draw the following conclusions:

\subsection{Accumulation of Innovation Plays a Stabilizing Role in Enterprise Innovation}

In all the models of Table 2, the significance of innovation accumulation (Pre) is high and stable. This shows that innovation accumulation has a stable and lasting influence on innovation, regardless of the length of the alliance relationship. Enterprises need to persevere in their efforts to improve innovation efficiency and quantity.

4.2 The Impact of Enterprise Network Characteristics on Innovation Is the Largest in the Second Year after the Alliance Window Period

In the full-variable model series $(1,3,5,7)$ of Table 2 , the number of significant variables is sorted like this: $\mathrm{N}_{\mathrm{p} 2}>\mathrm{N}_{\mathrm{p} 1}>\mathrm{N}_{\mathrm{p} 3}>\mathrm{N}_{\mathrm{p} 0}$. In the excluding-variable model series $(2,4,6,8)$, the number of explanatory variables is sorted like this: $\mathrm{N}_{\mathrm{p} 2}>\mathrm{N}_{\mathrm{p} 3}>\mathrm{N}_{\mathrm{p} 1}>\mathrm{N}_{\mathrm{p} 0}$. This shows that the influence of network characteristics on innovation is growing first and then diminishing. The effect is 0 at the end of the window period, increases in the first year, reaches its maximum in the second year, and weakens (or changes) in the third year.

Next, we focus on the analysis of the parameters involved in model 6.

\subsection{From (16) We Can See: Clustering Coefficient Is Positively Related to Enterprise Innovation}

The clustering coefficient calculated in this paper is a global parameter, which describes the completeness of small groups. For enterprises, the increase of clustering coefficient does not mean higher degree (degree) and network density. The positive coefficient of CC means that it plays a positive role in promoting innovation.

The closed three tuple refers to the fact that the three enterprises form a closely related small group, in which each enterprise has an alliance relationship with each other. The triangular structure facilitates the flow, collision, elicitation, multiplication, and feedback of information and other innovative resources. It can form network loops, while single chain or star structured can not. In the case of other unchanged parameters, the higher the ratio of closed three tuple, the more network loops. This will lead to some special innovative advantages, and more innovative behaviors.

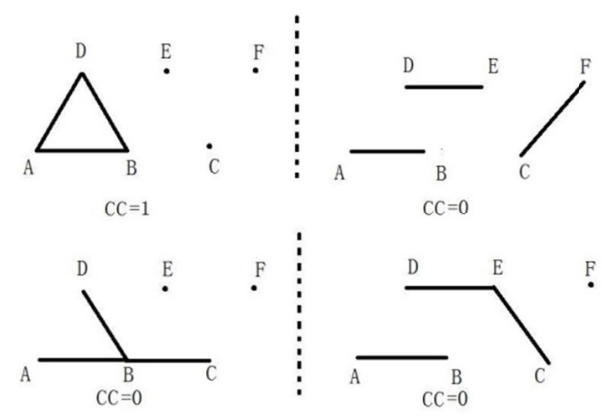

Figure 3. Diagram of the role of closed three tuple in innovation

Note. The total number of alliances in the chart is same. Assuming that information is transmitted through a nodle (enterprise), an increase (a) is obtained. If it is a closed loop, the information loop is finished after b times. In the Fig 3, 6 companies madie an innovative breakthrough (incomplete innovation, assuming the innovation value $=\mathrm{c}$ ). Innovative information is transferred through alliances and then returned to the enterprise, resulting in a proliferation of innovative values $(1+a) b c$. For $a=100 \%, b=2$, $c=0.5$, the final innovation values for four scenarios are: $16+16+0.5+16+0.5+0.5=49.5(\mathrm{CC}=1) ; 1+1+1+1+1+1=6,2+1+2+2+0.5+0.5=8,1+1+2+2+1+0.5=7.5(\mathrm{CC}=0)$.

\subsection{From (16), (18) We Can See: Betweeness Centralization Is Positively Related to Enterprise Innovation}

Betweeness Centralization is the individual parameter. Higher BC means that enterprise occupies more strategic passages and necessary places in the alliance network. Obviously, this will help enterprises to control more innovative resources. Theoretically, $\mathrm{BC}$ plays a positive role in the innovation of individual enterprises. From model 6 table 2, we can see that the coefficient of $\mathrm{BC}$ is significant positive. 


\subsection{From (16), (18) We Can See: Cluster Number/ Network Density Is Negatively Related to Enterprise Innovation}

In Table 2 and 4, the coefficients of the $\mathrm{CN}$ are unexpectedly negative and are very stable. Considering that $\mathrm{CN}$ is highly correlated with network density (correlation coefficient is 0.94 ), it means that the network density is negatively related to enterprise innovation. That is, when the network density increases, the number of enterprise innovation is declining. The explanation is as follows:

First, for firms with lower innovation accumulation, higher network density is beneficiall. This will promote the communication and diffusion of information, the acquisition of innovative resources, so that the accumulation advantages of old enterprise innovation will diminish. With the increase of network density, information flow among enterprises will increase, and possibility and convenience of innovation resources will also increase. For enterprises with higher accumulation of innovation, this means a long-time outflow of innovative wealth such as technology, experience and talents. This will improve the competitive enterprises' innovative ability, and relatively reduce their own innovative advantages. Considering that the network density calculated in this paper is the parameter of the whole industry, the higher network density implies that the industry has a tendency to encourage new-established enterprises to innovate actively. Lower barriers to innovation make it easier for newly established companies to achieve innovative success.

Second, the higher network density means that more alliances need to be built and maintained. The benefits of alliance relationships are not enough to cover costs. If the independent variable degree in Figure 1 is replaced by the network density $\mathrm{ND}$, then the innovation function is $\mathrm{f}(\mathrm{ND}), \mathrm{f}\left(\mathrm{ND}_{0}\right)=\mathrm{fmax}$. The $\mathrm{ND}$ value of the enterprise investigated in this paper is greater than the optimal value ND0, and $\mathrm{f}$ (ND) is located in the monotonically decreasing region.

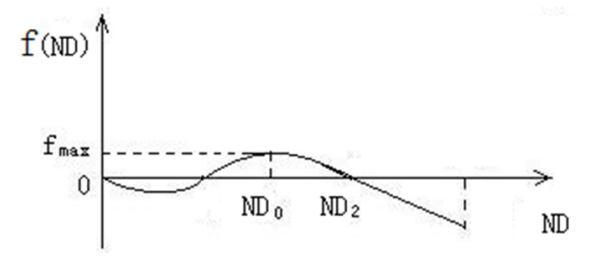

Figure 4. The innovation function $\mathrm{f}(\mathrm{ND})$ with ND as independent variable

\subsection{From the Formula (20), We Can See That There Is A Inverted U Shape Relation Between Average Path Length And Clustering Coefficient}

Average path length refers to the average step size of all enterprises that have direct or indirect alliance relationships. This index measures the transmission performance and efficiency of the network. the image of function (20) is as follows. When $\mathrm{APL}=1.535, \mathrm{CC}$ has a maximum value of 0.942 . Notice that both APL and CC are global parameters.

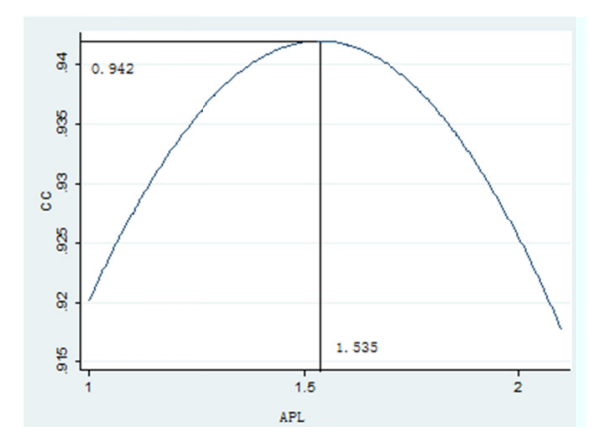

Figure 5. Inverted U shape relation between APL and CC

4.7 In (16) and (18), Effect of APL on Innovation Is Reflected in Two Forms: Negative Linear Relation and Inverted U Type Relation

We separate the APL part of (18) into APL-innovation function: F(APL).

$$
\mathrm{F}(\mathrm{APL})=13.58-6.513\left(\text { APL-1.444) }{ }^{2}\right.
$$




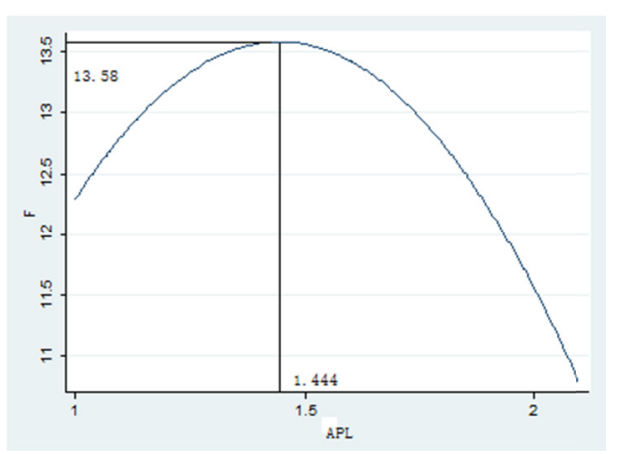

Figure 6. Inverted $U$ shape relation between APL and innovation(F)

When APL $=1.444, \mathrm{~F}(\mathrm{APL})$ has a maximum value of 13.58. When APL $>1.444$, the shorter the APL, the higher the network transmission efficiency, the more active the enterprise innovation. This is easier to understand. But when APL $<1.444$, with the increase of APL, the number of enterprise innovation is rising. We need to take into account the indirect transfer effect of the agglomeration coefficient CC. Compare (21) and (20), the symmetry axis $\mathrm{APL}=1.444$ and $\mathrm{APL}=1.535$ are very close. When apl $=1.5$, the $\mathrm{CC}$ and the innovation function are close to the maximum. Taking into account the positive correlation between enterprise innovation and $\mathrm{CC}$, the author speculated that the inverted U type relationship between APL and enterprise innovation is mainly achieved through the transfer of CC.

\section{Summary and Suggestions}

In this paper, a simplified innovation function is proposed, and its properties are analyzed preliminarily, and a qualitative function diagram is given.

It can be concluded that the structure parameters of allied innovative network of China's energy-saving and environment-protection enterprises exert a definite influnce upon enterprise innovation from 2000 to 2013. The accumulation of innovation has a lasting impact on innovation. Meanwhile, the network structure parameters also have significant lag effects on innovation(lag 2 years). The different network structure parameters reflect different types of networks and different positions. Innovation accumulation, $\mathrm{CC}$ and $\mathrm{BC}$ are positively related to enterprise innovation, $\mathrm{CN}$ and $\mathrm{ND}$ are negatively related to enterprise innovation, and there is an inverted $\mathrm{U}$ shape relationship between the APL and enterprise innovation.

We should improve the macro and micro environment of enterprise innovation, the structure of alliance network, the completeness of small groups and network efficiency of innovation alliance, so as to improve the overall innovation level.

1) Government should encourage enterprises to innovate, improve the innovative environment, and raise the accumulation of innovation in energy-saving and environment-protection industry.

2) We should appropriately control the network density of China's energy-saving and environment-protection industry. Enterprises should not blindly build more alliances in order to avoid excessive costs. The enterprises with high accumulation of innovation should control the diffusion of innovation resources, and avoid providing free resources for others. New enterprises should seize the opportunities of the time and actively make use of external innovation resources to make breakthroughs in innovation.

3) Enterprises should form more cooperative small groups and increase the proportion of closed three tuples. At the same time, the government should introduce incentive policies to improve the overall agglomeration factor of the industry.

4) The Average Path Length of the whole industry should be maintained at about 1.444, not too big or too small, in order to obtain the maximum Clustering Coefficient and enterprise innovation.

5) Enterprises should try their best to improve their BC, and to act as the intermediary and bridge of information communication and resource exchange.

Finally, it still needs careful consideration whether the conclusion of this paper is only valid for the recent development trend of China's energy-saving and environment-protection industry, and whether it can be extended to other industries or other countries and regions. Follow-up studies can cover the industries data in different periods, or extend the scope of the enterprise to other industries or countries and regions, or optimize 
the model by taking into account other network structure parameters, enterprise characteristics variables and macro factors.

\section{Acknowledgments}

This paper is funded by National Social Science Foundation of China: Clique Studies in Alliance Innovation Network of Strategic emerging industries in China (Project No. 15CGL007). My hearty thanks go to my colleague Dr. Zheng Xiangjie for his selfless help in my topic selection and research methods.

\section{References}

Anand, B. N., \& Khanna, T. (2000). Do firms learn to create value? The case of alliances. Strategic Management Journal, 21(3), https://doi.org/10.1002/(SICI)1097-0266(200003)21:3<295::AID-SMJ91>3.0.CO;2-O

295-315.

Burt, R. S. (1994). Structural holes: The social structure of competition. The Economic Journal, 40(2).

Burt, R. S. (2000). The network structure of social capital. Research in Organizational Behavior, 22, 345-423. https://doi.org/10.1016/S0191-3085(00)22009-1

Chen, X. S., Wang, Z. W., \& Chen, J. (2016). The influence mechanism of external knowledge network embeddedness on firm's design innovation performance: the mediating process of meaning innovation process. Technology and Economics, (07), 27-31+96.

Coleman, J. S. (1988). Social capital in the creation of human capital. American Journal of Sociology, 94, 95-120. https://doi.org/10.1086/228943

Devi, R. G., \& Madhavan, R. (2001). Cooperative networks and competitive dynamics: A structural embeddedness perspective. Academy of Management Review, 26(3), 431-445.

Fan, L., Zhong, S. H. (2003). Cost change analysis of enterprise technology alliance. Advances in science and Technology and Countermeasures, 20(17), 21-23.

Freeman, L. (1979). Centrality in social networks: Conceptual Clarifications. Social Networks, 1(3), 215-239. https://doi.org/10.1016/0378-8733(78)90021-7

Granovetter, M. (1984). Economic action and social structure: The problem of embeddedness. American Journal of Sociology, 19(3), 481-510.

Gu, Y. X., Sun, L. Y., \& Hou, G. (2001). The establishment and operation cost analysis of enterprise alliance and enterprise group. System Engineering Theory and Practice, 21(8), 75-79.

Hansen, M. T. (2002). Knowledge networks: Explaining effective knowledge sharing in multiunit companies. Organization Science, 13(3), 32-250. https://doi.org/10.1287/orsc.13.3.232.2771

High, T. S., \& Liu, L. (2016). Discharge enterprise alliance international research and development will help to breakthrough innovation? Science research Management, 37(1), 48-57.

Inkpen, A. C., \& Tsang, E. W. K. (2005). Social Capital, Networks and Knowledge Transfer. Academy of Management Review, 30(1), 146-165. https://doi.org/10.5465/AMR.2005.15281445

Jin, X. T., \& Li, L. (2005). Beyond transaction cost theory and enterprise strategic alliance. Business Economics, (5), 8-10.

John, Q. D. (2017). How central is too central? Organizing interorganizational collaboration networks for breakthrough innovation. J Prod Innov Manag, 34(4), 526-542. https://doi.org/10.1111/jpim.12384

Julia, L. L. et al. (2009). Network Embeddedness and Technology Transfer Performance in R\&D Consortia in Taiwan. Technovation, 29(11), 763-774. https://doi.org/10.1016/j.technovation.2009.05.001

Li, H. Q. (2007). Research on the motivation of the establishment of strategic alliances. Integration of resource perspective and transaction cost perspective. Reform and Strategy, (7), 32-35.

Shen, Z. Z., Jing, J. S., \& Xu, C. Z. (2003). Transformation of the enterprise alliance paradigm for knowledge competition - product alliance to knowledge alliance. Journal of University of Electronic Science and Technology (SOCIAL SCIENCE EDITION), 5(2), 50-54.

Song, J., Sun, Y. L., \& Chen, J. (2017). Research on the effect of network practice based on regulatory orientation on cooperative innovation performance. Science and Technology Management, (2), 127-135.

Song, L. P. (2014). Research on performance evaluation and innovation capability upgrading of regional innovation system. China University of Geosciences. 
Wang, J. Y., Liu, Y. Q., \& Ari, K. (2017). industrial network technology innovation from the perspective of social network. An empirical study of China's new energy automotive industry alliance. China Science and Technology Forum, (5), 186-192.

Wei, J., \& Xu, L. (2014). Dual embeddedness of knowledge networks, knowledge integration and innovative capabilities of cluster enterprises. Journal of Management Science, 17(2), 34-47.

Wu, X. B., Xu, G. N., Du, J. (2011). Network Embeddedness: Organizational learning and innovation. Science Press.

Xiang, Y. S., Wei, J., \& Zheng, X. Y. (2016). Research on the effect of multiple embeddedness on innovation capability of cluster enterprises. Research management, 37(10), 102-111.

Xie, Y. P., \& Jing, W. (2017). Research on the influence of alliance relationship on innovation performance under technological uncertainty. Science and Technology Management, (5), 60-71.

Zhang, S. Y., Guo, Q., \& Yuan, L. (2001). Internal reasons for the formation of strategic alliances. Soft Science, 15(4), 6-10.

Zhang, Y. H., \& Peng, J. Q. (2016). The influence of network characteristics of technological small and micro enterprises alliance on enterprise innovation performance based on the mediating role of innovation resources. Science and Technology Management Research, 36(17), 140-147.

Zhao, Y., \& Guo, X. W. (2012). Research on the influence of structure holes on enterprise innovation performance in alliance network. Based on China home audio and video equipment manufacturing enterprise alliance network. Science and Technology Progress and Countermeasures, 29(17), 76-81.

Zhao, Y., \& Wang, Q. (2013). Empirical research on the influence of the small world of alliance network on enterprise innovation. Based on the analysis of communication equipment industry in China. Chinese Soft Science, (4), 108-116.

Zhao, Y., \& Wang. Y. N. (2017). The stronger, the narrower. Evidence from the innovation network of inter enterprise alliances. Based on the characteristics of resources and structural features. Science and Technology Management, (5), 117-127.

Zhao, Y., \& Zheng, X. J. (2013). Network agglomeration, connectivity and enterprise knowledge innovation. Based on the alliance network analysis of 10 high-tech industries in China. Science and Technology Management, 34(3), 23-32.

Zhao, Y., Feng, W. Y., \& Zheng, X. J. (2016). Influence of coupling of factions and knowledge flows on innovation capability of alliance networks. Research Management, 37(3), 51-58.

Zheng, X. J. (2017). Network Embeddedness and Firm Innovation: An Empirical Research on Strategic Emerging Industries in China. International Journal of Business and Management, 12(5).

Zhong, S. H. (1998). Technology Alliance: type, benefit and cost analysis. Science and Technology Management, (8), 25-27.

Zhou, J. (2000). Study on the competitiveness of enterprise strategic alliances: A Perspective of core competence. Nankai Management Review, 3(1), 42-48.

\section{Note}

Note 1. A Development Plan of the National Strategic Emerging Industry From 2016 to 2020. Chinese government website. http://www.gov.cn/zhengce/content/2016-12/19/content_5150090.htm

\section{Copyrights}

Copyright for this article is retained by the author(s), with first publication rights granted to the journal.

This is an open-access article distributed under the terms and conditions of the Creative Commons Attribution license (http://creativecommons.org/licenses/by/4.0/). 